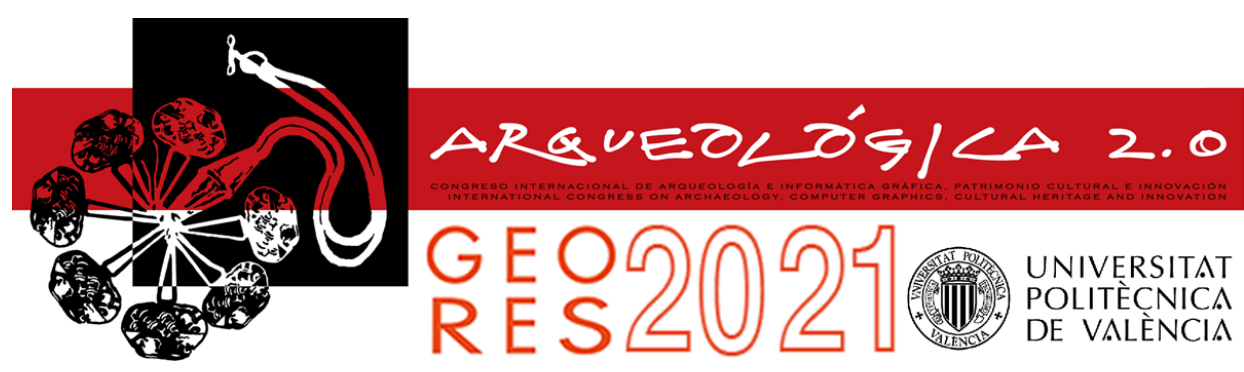

Proceedings of the joint international event $9^{\text {th }}$ ARQUEOLÓGICA

$2.0 \& 3^{\text {rd }}$ GEORES

Valencia (Spain).

26-28 April 2021

\title{
THE TAORMINA THEATER: THE DIGITAL SURVEY SYSTEM OF KNOWLEDGE OPEN IN TIME
}

\author{
Giuseppe Di Gregorio \\ Dipartimento di Ingegneria Civile e Architettura, Università degli Studi di Catania, Via Santa Sofia 64, 95125 Catania, Italy. \\ giuseppe.digregorio@unict.it
}

\begin{abstract}
:
In Sicily, there are 19 show venues including ancient theaters and theatrical architectures. Many of these structures are fully functional and subject to visitor flows such as the theater of Syracuse and that of Taormina. They are object of interest and curiosity, revealed in the eighteenth century during the Grand Tour by travelers and landscape painters, in the last twenty years they have become reasons for study in various scientific areas as from acoustics to archeology, always passing through digital surveying. Studied through classical photogrammetry, structure from motion (SFM), 3D laser scanner, their representation as well as by increasingly refined and detailed two-dimensional graphics, makes use of 3D representations and techniques of virtual reality (VR) and augmented reality (AR). Due to their particular geometry, the need for studies and researches is considering essential to deepen the methods of the surveys and plan their developments. Examples and problems for the archaeological survey are reporting with the aim of critically evaluating the current state of the art of 3D survey, the potential and possible future developments. The present study shows the results obtained for the survey of the Taormina Theater (ME) and an in-depth analysis of the versura environments.
\end{abstract}

Keywords: digital archaeology, cultural heritage, digital survey, 3D reconstruction, photogrammetry, drawing

\section{Introduction}

The Taormina Theater (Fig. 1) has a diameter of the cavea equal to about $109 \mathrm{~m}$, that of the orchestra equal to about $35 \mathrm{~m}$, the current number of seats is 4,500 , the plant is about $50 \mathrm{~m}$ in width and $120 \mathrm{~m}$ in length, for height it develops for about $20 \mathrm{~m}$. Slightly smaller than that of Syracuse in size, it exceeds it in terms of the number of visitors equal to 888,353 in 2019 , against the 692,186 of the Syracuse Theater, contending in alternate periods for the primacy for Sicily with the archaeological area of the valley of the temples in Agrigento, which counts 954,988 visitors in 2019. If you think that in 2010 the number of visitors was 592,468 , we understand that the trend is constantly growing, but it should also be observing that it is for all the archaeological museum sites of Sicily Island. These considerations make us understand the growth of an increasingly culturally evolved tourism, from which the importance in both directions derives, on the one hand, the need for increasingly in-depth scientific studies (Benedetti, Gaiani, \& Remondino, 2010), on the other of dissemination and fruition products such as virtual reality (VR) and augmented reality (AR). This study gives the results of the survey carried out for the Greek-Roman theater of Taormina and the in-depth study for the development of the versura environments. For these two environments, different softwares was used, both for acquisitions with active sensors, and via SFM for terrestrial images with known problems, such as initial filtering, cloud decimation, elimination of external and internal noise, saturation of holes, removal of points of low quality, etc.

\section{Digital survey, variants and invariants}

The definition of analogical indicates the comparison between operations based on their describability through logical similarities, defining the imperfect correspondence between phenomenon and model, often referred to as relations of formal, figurative or material mimesis. The image contained in a photograph intended as a representation of an object is always analog: its support can be digital or analogical. Structure From Motion (SFM) and dense Matching, Multi-View Stereo (MVS) multiimage photogrammetry transform two-dimensional analog models (photographs) into a continuous 3D digital model. The exponential acceleration of the last ten years has seen the evolution in different directions of studies concerning digital technologies. The need to safeguard the heritage of artistic, architectural and archaeological heritage has led to the development of increasingly innovative research systems, suitable for documentation, knowledge and survey, intended as a basic prerequisite for cataloging, study and protection. The tower of Babel of the many management, processing, post processing, $3 \mathrm{D}$ creation software, with their interchange formats that are sometimes mutually compatible and others not, constitutes a universe in continuous evolution. The direction taken by a single study depends on the objectives to achieve, but essentially everything can be traced back to two directions, the first is based on 
knowledge and envisages a scientific or cultural result for specialists as an objective, the second goes in the direction of dissemination and fruition. In the process of representing the Cultural heritage, there are variants and invariants. The survey, the measurements, the laser scanning, the graphic representation are invariant over time. The software, the applications for clouds post processing, for thinning, the software for photogrammetry single image, multi-image, SFM, MVS, for the creation of VR and AR are variants. More generally, the measurement data constitute primitives that describe the object at time to of the survey, certainly invariable, if the meaning has changed over time, it must sought in the dynamic analysis of the object. More simply, a drawing or a dated 3D Laser scan retains its validity: a current laser scanner, although faster than the first generations, will obtain the same metric data. What varies is the finally result through the post processing routines, creation of $3 D$ environments, semantic segmentation, pipelines, solutions, algorithms (Grilli, \& Remondino, 2019). Emphasis is increasingly on the studies innovation, but it is believed that with the speed of development of digital applications, studies on the variable aspects of the representation process, that is post processing, of the digital data of the Cultural Heritage it is constantly renewed. Essentially the results of $3 D$ representation, modeling and VR of a few years ago need to be rework. It should also observed that in the process of creating virtual VR environments a distinction must made between visualization and interaction.

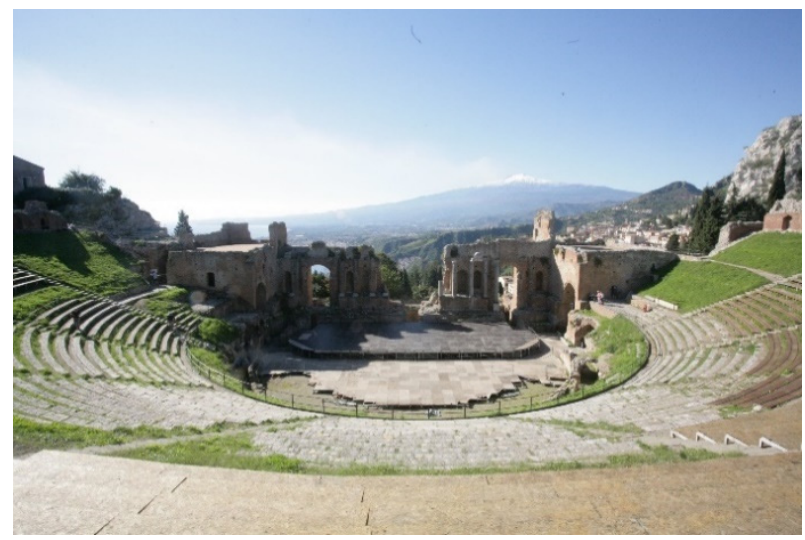

Figure 1: The Taormina Theater, in the background the Etna volcano and the sea.

\section{Brief diachronic notes on the theatre}

Here are some diachronic information, with the sole purpose of framing the evolution of the various parts. The theater stands on the slope of monte Tauro, in the eastern part of the city, on the site that was originally occupied by the agorà. According to the most authoritative sources, the birth of the theater dates back to the third century b.C. in the hellenistic period by Hieron II of Syracuse. The origin is documented by the remains of the blocks of Greek origin under the current scene and by some Greek inscriptions on the steps where the name of Philistis, wife of Hieron II, is engraved. Three phases have been hypothesized, to the first theatrical system is attributable a theater smaller than the current one, enriched in the top of the cavea of a small temple (of which today there are only a few remains) and a scene (skené) rotated due to an about three degrees of the axis with respect to the Roman structures. The second theatrical system is attributable to an early Roman phase. It sees the introduction of the new front scene (scaenae frons), with a hypothetical rectangular plan, consisting of three archways (two hospitalia and a valvae regiae) and two side walls, to delimit the length of the scene (pulpitum). The two walls that intersect the analemmata walls delimit the two parascaeni, without cover at this stage, which allowed the passage to the orchestra area through the paradoi. Finally the expansion of the cavea led to the introduction of intermediate accesses that led to the respective precinctions (praecinctio) in a total number of three. The third theatrical installation, from the second Roman phase, brings transformations and new introductions. Among the transformations the enriched scene, the enlargement of the scene and on the sides the covering with large barrel vaults of the parascaenia giving life to the so-called versura, among the new introductions are the creation of a portico behind the scene (porticus postscaenium) and two large semicircular corridors crowning the cavea. The cavea has maintained the horseshoe shape, with the two external wings extended towards the scene, originally it was organized in nine wedges interspersed with eight stairs and the ambulatory divided it horizontally into two sections, the upper part closes with a hemicycle crowning, consisting of a double arcaded gallery occupied by wooden steps. On the internal front towards the cavea, there are eight entrances (vomitoria) in correspondence with the stairs that allow access to the cavea, the central wedge is maintained on the axis of symmetry according to the Greek manner. In the late imperial age, to allow the orchestra (conistra) to be transformed into an arena, the scene was suppressed, the first orders of seats removed and an annular cryptoporticus was created. The circumference that inscribes the orchestra is separated from the front of the scene at one third of the radius, the underground corridor coming from the scene building is arranged on the central axis of symmetry. The scene building is the only one present in Sicilian theaters, althought largely incomplete. It has a front scene consisting of 3 orders originally decorated with niches, statues and Corinthian columns, supporting the architraves. The lower order remains partially preserved, the building currently represents one of the favorite destinations of visitors with archaeological knowledge (Gallo, 1773).

Regarding the materials were used local limestone and brick. With an act of 1465 , the viceroy of Sicily Lope Ximénez, in the name of King John II of Aragon, granted Guglielmo Zumbo the ancient theater of Taormina, referred to as: "quoddam hedificium anticum et dirutum [...] vulgariter appellatum Iu goliseu alias Iu palazu", with permission to build inside but without damaging the monument (Muscolino, 2020). The first historical images belong to the period of the Grand Tour, and they see two opposing groups of protagonists. On the one hand landscape interpreters of the ruins who have given us drawings of an epic state of affairs of their time like LouisJaean Desprez and Louis Francois Cassas, on the other, artists such as Jean-Pierre Houël (Houel, 1977) and Andrea Gallo (1773) with the drawings of their reconstruction hypotheses (Fig. 2). 


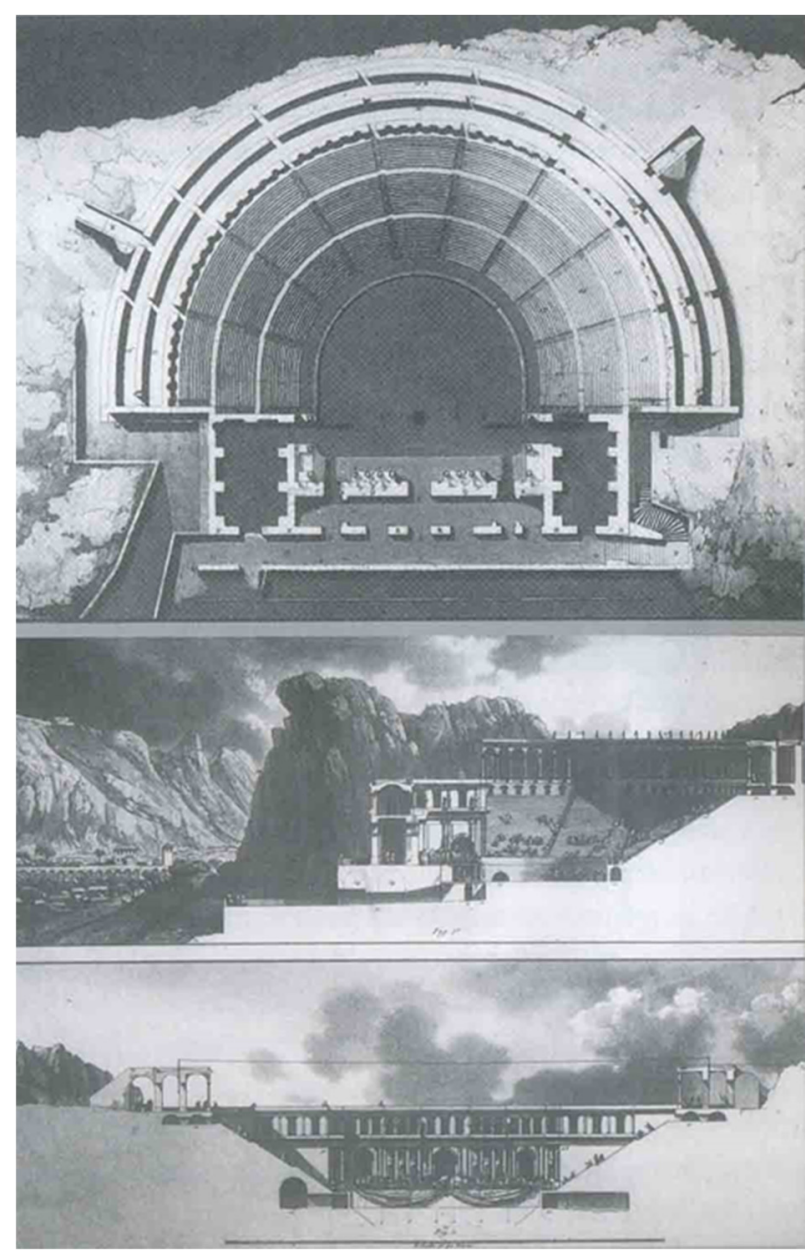

Figure 2: Plan and section of the theater according to the hypothesis of $\mathrm{J}$. Houel.

\section{The versurae}

In the Greek period the spectators accessed the seats on the steps by means of the parodoi, openings located between the stage and the stalls. The stage and the proscenium were separated from the stalls: two independent bodies from each other, of these lateral spaces free today nothing remains. The romans were not particularly fond of dramatic performances, famous and flourishing in the Hellenistic period, so at the end of the $2^{\text {nd }}$ century a.C. the orchestra was thus reduced and transformed into an arena for gladiator games and pits were dug, while the lateral parodoi were covered with large vaulted structures and transformed into vomitoria. Later were also suppressed the vomitoria, the scene wall and the covered corridor behind them were connected to the great Roman vaults with large internal walls. The new constructions, called versurae (or more commonly called porticoes or hallways), formed at the two corners of the theater, effectively welded the scene to the stalls (cavea) (Lo Faso, 1842). Definitively abolishing the trace of the two Greek parodoi and the Roman vomitoria that they tried to preserve, in part, the original structure, both in form and in the function of accompanying the public inside the theater. At the time when the theater underwent this further transformation, all accesses were transferred to the upper part of the building and connected, at the lower level, by means of stairs and new floors supported by the vaults of the two versurae (Rizzo, 1983).
On the north-west side, the insertion of new structures has almost closed an opening of the theater period, in the south-east side, the restructuring coincided perfectly with the original plan. The main staircase, which rises to the side of the east entrance hall, still today has three turns that all end with a door that leads into the auditorium or terrace above the versura. The staircase ends in the external corridor of the second portico, from which, through the first, one came directly to the cavea. Next to the outer wall of the west side there is another staircase, which gives access to the terrace placed as an extrados above the vault that formed the vomitoria. In both terraces, the plebs found their place during the games.

The versurae are not only an element of discontinuity with the architecture of the past, but they represent the radical change in Roman society of the vision of the theater: from an introspective and certainly cultural place in the time of the Greeks, it becomes in the roman times an arena for bloody games and shows sumptuous.

The versurae were never for the public: their new function was to bring together and host the actors who therefore used them as a dressing room and storage for stage tools. The northern walls of the versurae were the limit of the stalls on which the spectators sat and they were been entirely closed, as was their external wall, which had no opening. Their insertion in the terminal part of the auditorium alters the reading of the analemma wall, an element of differentiation between the two types of theater. According to the tradition, the inhabited part of the theater, relating to the concession of 1465 , coincides with the two versurae and part of the scenic building.

\section{The survey methodology}

The choice for the survey was been based on a mixed methodology integrated with TLS (Terrestrial Laser Scanner) instrumentation and photogrammetry, in order to have both quality survey data based on active sensors and dense clouds based on photogrammetric data. For the most extensive parts of the survey, it was preferred to use only the TLS active sensor instrumentation, such as the laser scanner in order to have structured metric data. For the smaller objects, both the previous one and the multi-image photogrammetric technique were been used, to compare and integrate the results. Thus for the internal parts of the versurae, so as the remains of the annular barrel vault of the hemicycle both the Structure from Motion (SFM) and the TLS methodology were used, for the cavea, the orchestra, the scene, the versurae. A total of twenty-seven stations were performed (Fig. 3), some with multiple scans, of which eleven in the upper corridor (Figs. 4-6), four in the west, three internal and one external, five in the east, three internal and two external, two along the south side of the scene, four along the stage, one in the center of the orchestra (Fig. 7). The instrument used is a Leica Geosystem HDS laser scanner, with a range of $300 \mathrm{~m}$, and a scanning field of $270^{\circ}$ vertically and $360^{\circ}$ horizontally. The entire model was merged using the Cyclone software from Leica Geosystem (Fig. 8), but for the graphic restitutions (Fig. 9) of the various parts, single scans were used or only the clouds necessary to define the parts, as in the case of the versurae (Fig. 10) or of the scene. The reason for this choice is due to the considerable size of the data file. The automatic decimation procedures of the Cyclone software by Leica and JRC 3D Reconstructor by Gexcel (Scarciotta 
2009; Raimondo G. F. 2009) were used separately, other attempts were made with Cloud compare. In the archaeological heritage sector, the procedures for decimation and automatic thinning of point clouds, must be used with particular caution, since along the vertical, horizontal and curved surfaces even the most modest variation of the order of a few centimeters can be a reason for interest and investigation for the research and cultural and scientific dialogue (Malinverni et al., 2019).

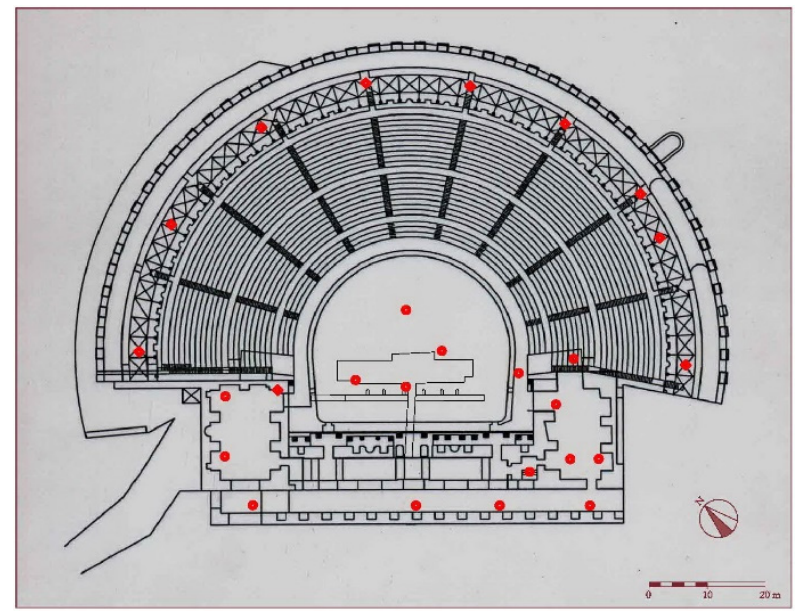

Figure 3: Position of the 28 stations performed with the laser scanner.

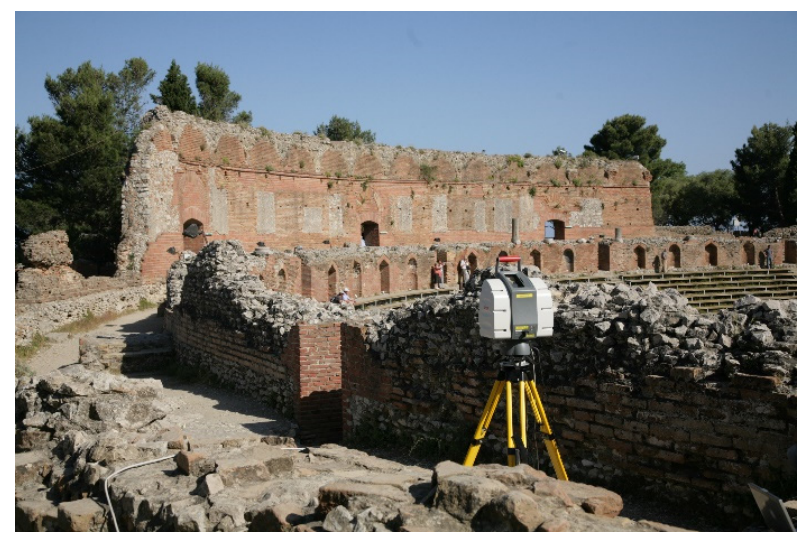

Figure 4: Station from the upper corridor.

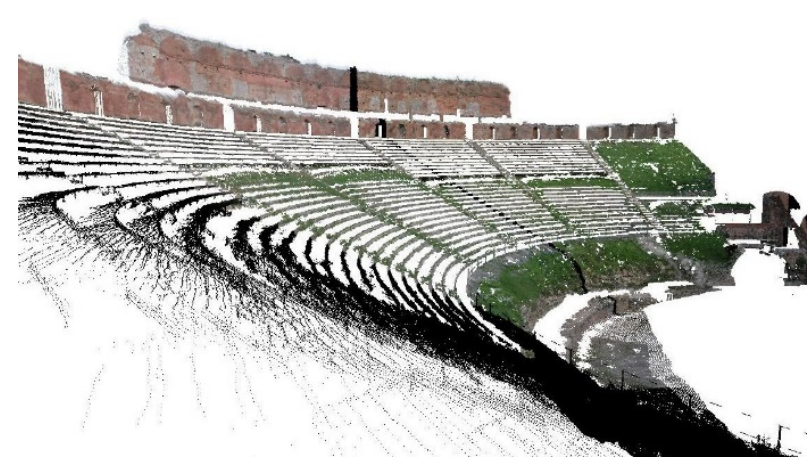

Figure 5: Scans of the upper zone.

The situation is different for the processing of continuous $3 \mathrm{D}, \mathrm{VR}$ and AR models, where the processing must be managed by multiscale hierarchical levels. In the archaeological survey, unlike the architectural one, there are no fundamental geometric references (horizontality, verticality, symmetries, parallelisms), which guide the restitution of a survey. As far as survey is concerned, the new methodologies are based on the use of $3 \mathrm{D}$ laser scans that combine high precision and versatility ensuring high quality detection and optimization of working times. The possibility of creating, starting from the point cloud, high-precision digital three-dimensional models, allows the monitoring of complex organisms, the creation of virtual museums, restoration. The many possibilities offered by this new technology for archaeological surveying, have not been exploited fully yet. Archaeological artefacts, are often characterized by irregular, discontinuous geometries and these make it difficult to identify specific reference elements for a geometric and material survey (Farella, Remondino, \& Torresani, 2019).

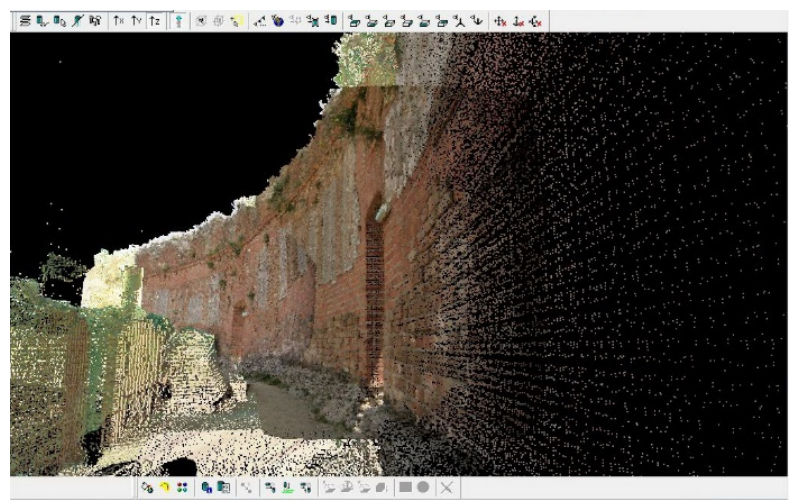

Figure 6: Scans of the upper corridor.

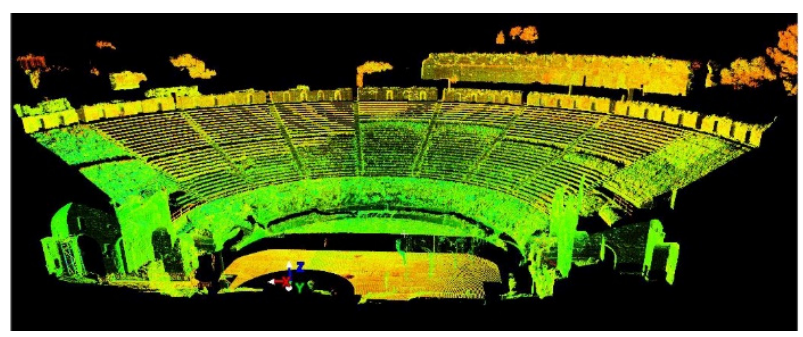

Figure 7: The scans of the cavea.
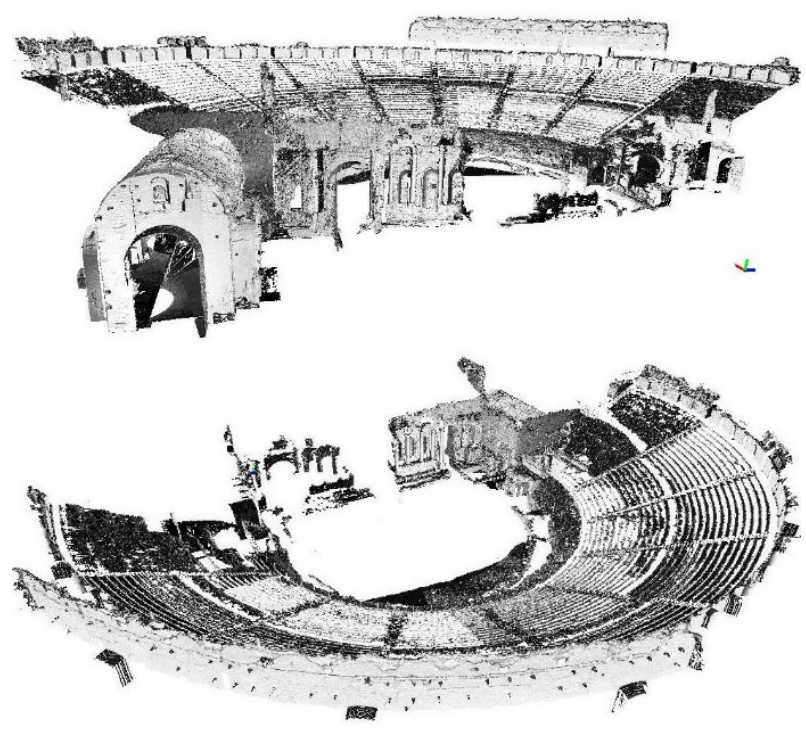

Figure 8: The union of the clouds, the cavea with the northwest side, from two different views. 


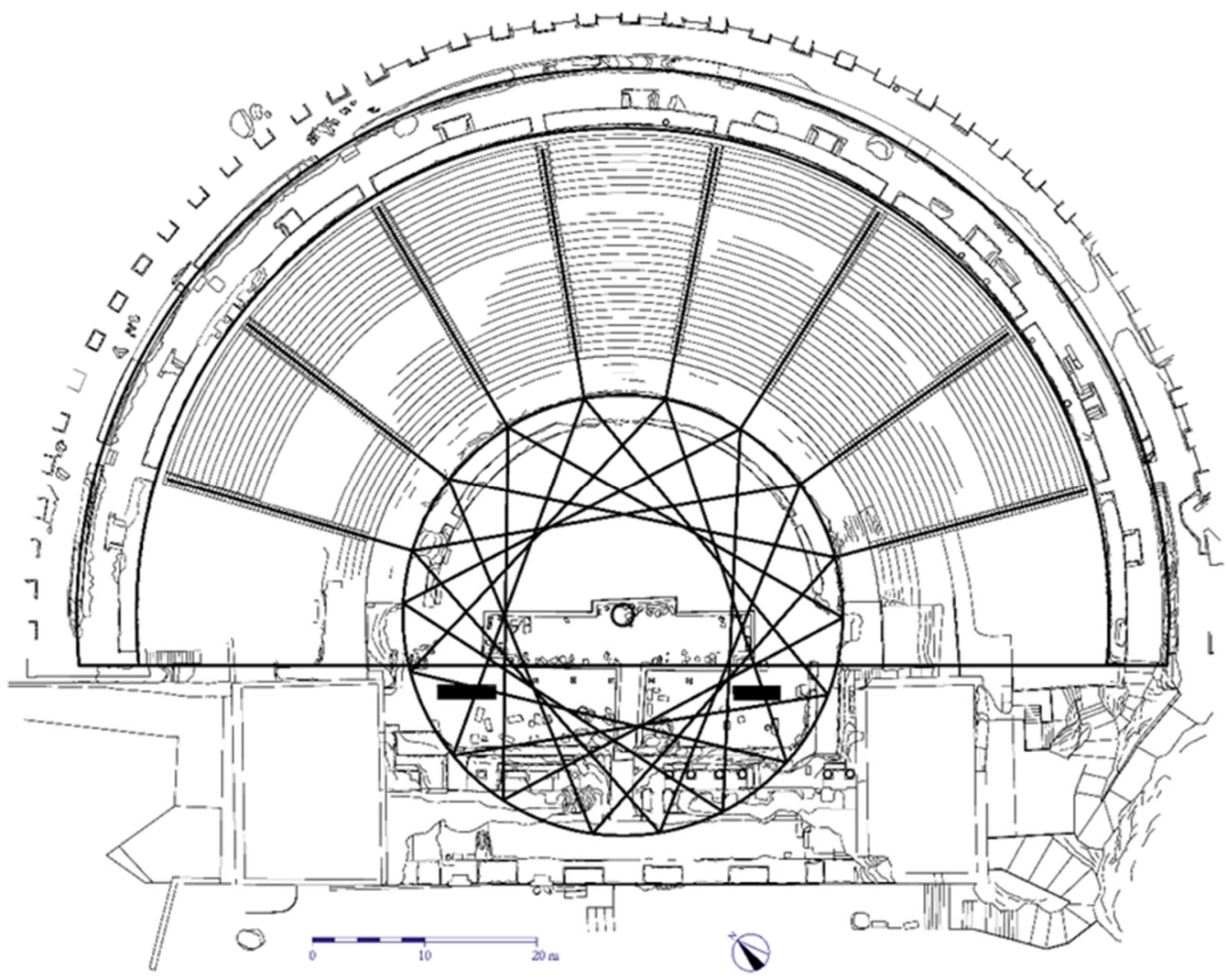

Figure 9: Theater plan and the geometric hypotheses of Vitruvius.

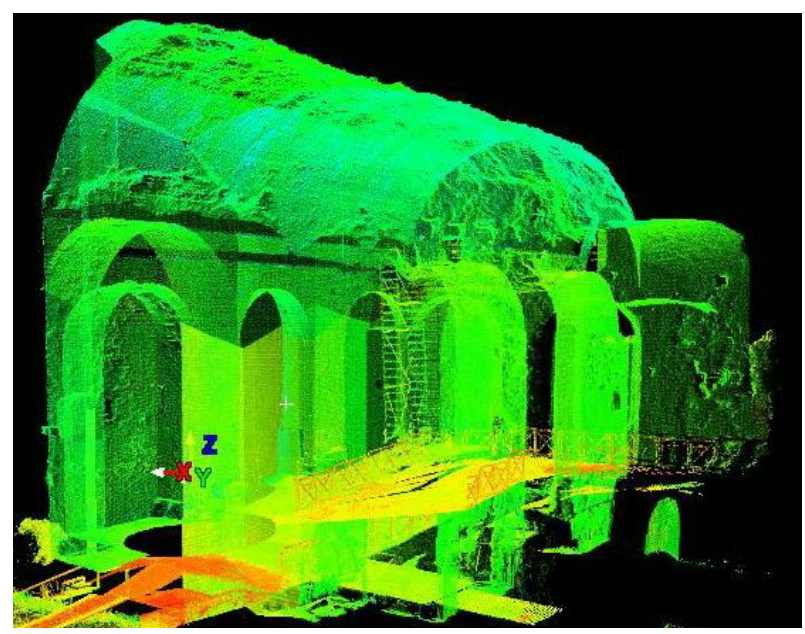

Figure 10: The point cloud of the northwest versura.

\section{The versurae}

The studies performed on the versurae (Fig. 11) have allowed us to find some results on their geometric conformation and the processing of 3D models. With reference to the southeastern side, the difference in size between the niches of the eastern and western walls is immediately evident. The modular searches have resulted that the one facing south-east is been modulated according to the ancient Greek foot unit, equal to $30.8 \mathrm{~cm}$ each niche is equal to 10 feet, also defined as kalamos or akaina that is about $3.08 \mathrm{~m}$. The projection separating the niches is equal to half of the module. On the opposite wall, the openings are wider and for the two equal there is a modulation equal to 12 times the roman foot, defined in the ratio of $29 \mathrm{~cm}$, therefore a total of $3.48 \mathrm{~m}$. The septum that divides them is about half, the third arc, which see the scene, is equal to about 13 times the Greek foot. The width of the versura equal to about $7.00 \mathrm{~m}$ is set on the roman module. The results obtained lead to various hypotheses, but the simplest is the definition of the Greek and Roman parts. The eastern wall with its niches already existed in the Greek period from which also the shorter length derives, probably arriving at the border with the analemma wall, then in the Roman phase, the wall was incorporated into the environment dimensioned with the "new" units of measurement. There is no symmetry between the two versures, nor correspondence between the dimensions, it should been observed that in the other versura, the north-west one, the north wall is occluded and separated from the rest.

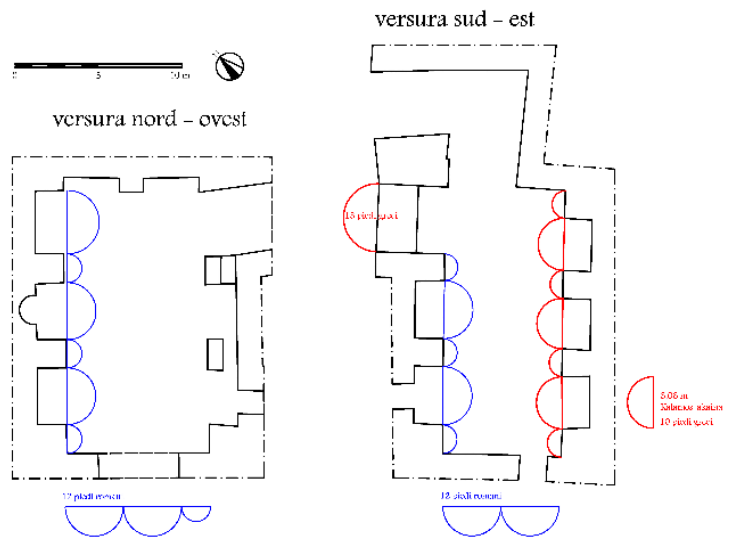

Figure 11: Modulation according to the ancient units of measurement. 
The studies carried out have shown dimensional matrices for the north-west side that can been traced back to the Roman period only. We do not know if any transformations place by the Zumbo family, following the concession of 1465 . Some aspects were been processed from the clouds obtained with TLS active sensors, including automatic decimation, without losing significant information, segmentation attempts and extraction of profiles with automatic procedures (Matrone et al., 2020). Through the software Cloud Compare, the qualitative data between the clouds obtained with photogrammetric methods (SFM) and those with laser scanners were been compared. The extraction of the profiles (Figs. 12 and 13) made it possible to verify and measure some degradations present in the barrel vault of the north-west versura. The extraction of the cloud with the SFM photogrammetric method with the Metashape software allowed to obtain about 50 million points with mediumhigh settings of the processing parameters, the initial photographic set included 113 images of which 109 aligned, with processing with Zephyr of 3DFlow 105 of 127 images were aligned, the Ground Sample Distance (GSD) was calculated for both alignments for a significant sample of photos. Taking into account the parameters of the photographic sensor equal to $25.8 \times 23.9 \mathrm{~mm}$, the GSD was equal to $2.3 \mathrm{~mm} / \mathrm{pixel}$ which for average object distances of about $7.5 \mathrm{~m}$ means an average image coverage of $10,88 \mathrm{~m}$ wide and $7.05 \mathrm{~m}$ high, valid values for the survey purposes and compatible with the quality of the 3D laser scanner survey. The resulting dense clouds were processed with mesh and texture (Figs. 14 and 15). The laser scanner cloud recorded 18 million points. The two point clouds were then evaluated with the Cloud Compare software. The restitution results are showed in Figures 16 and 17.

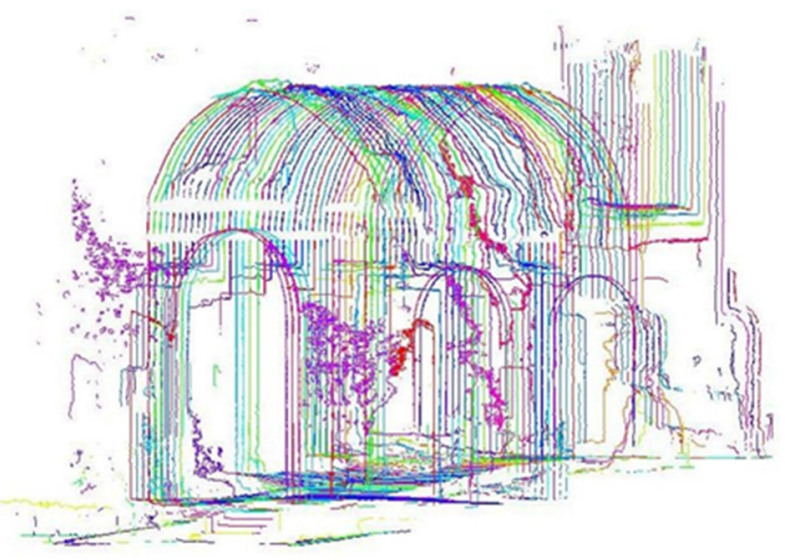

Figure 12: the north-west versura automatic extraction of profiles.

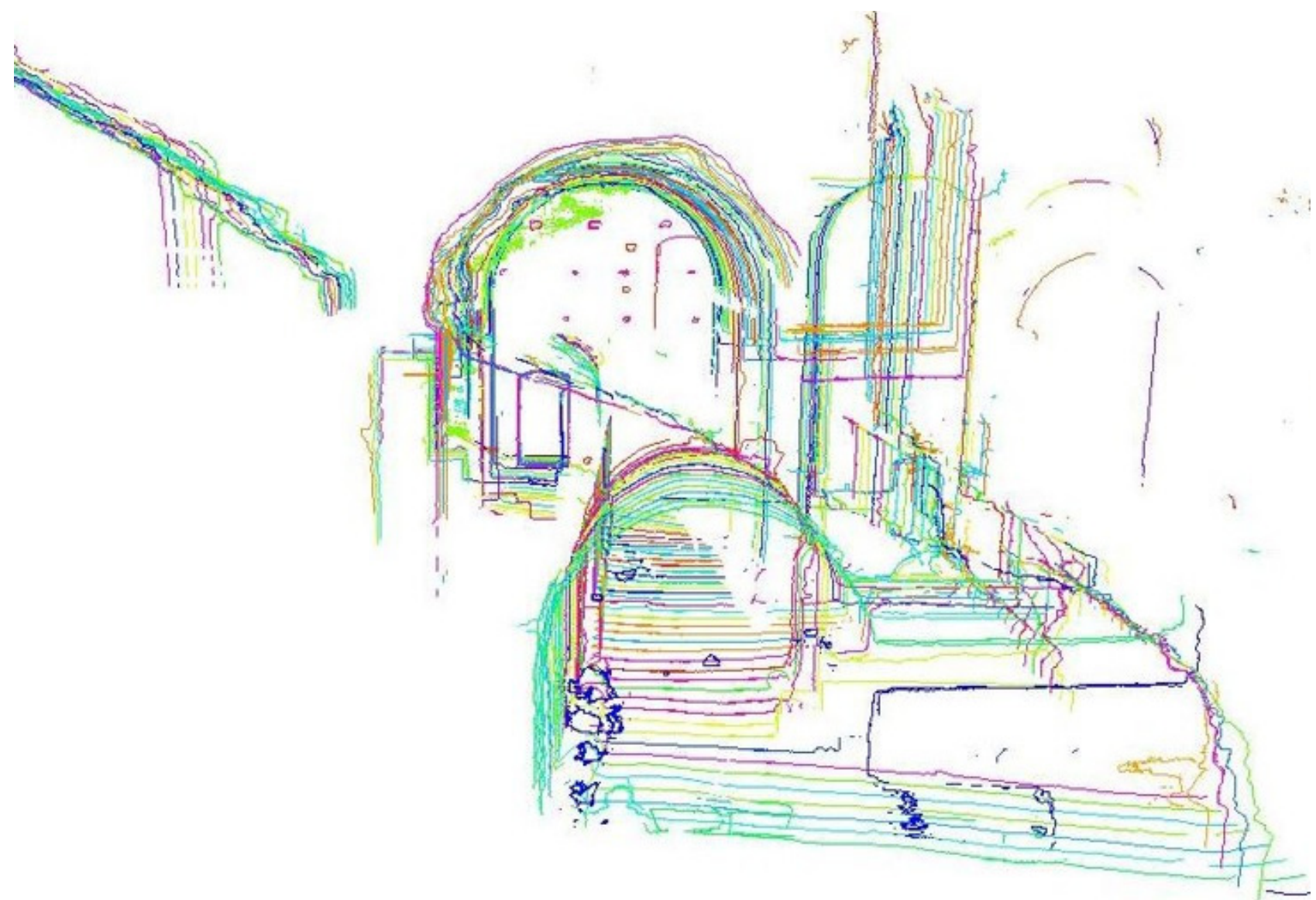

Figure 13: South - east versura, automatic extraction of profiles. 

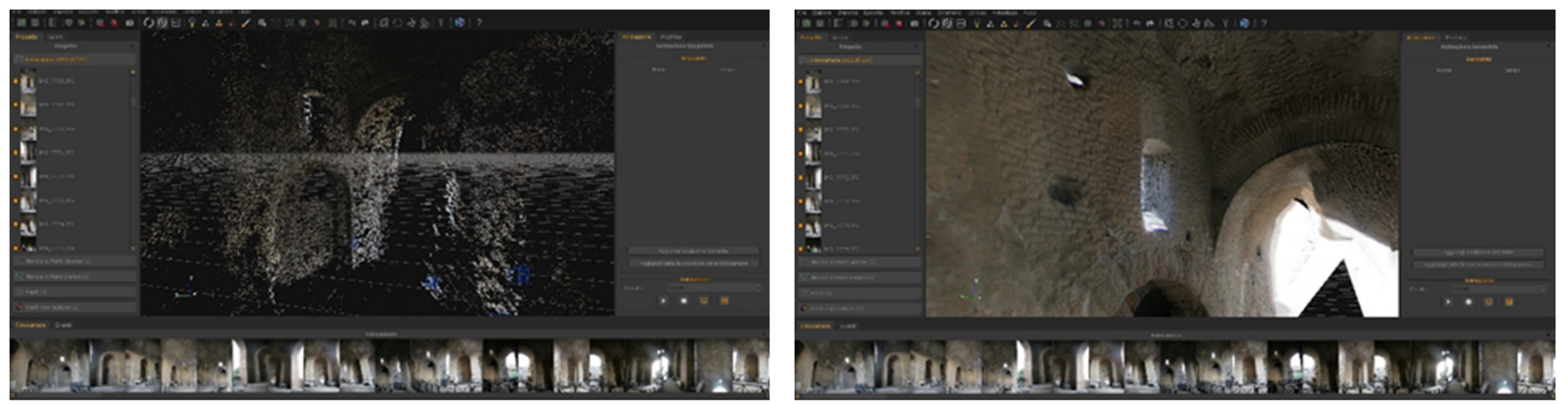

Figure 14: Northwest versura, SFM processing with Zephyr.

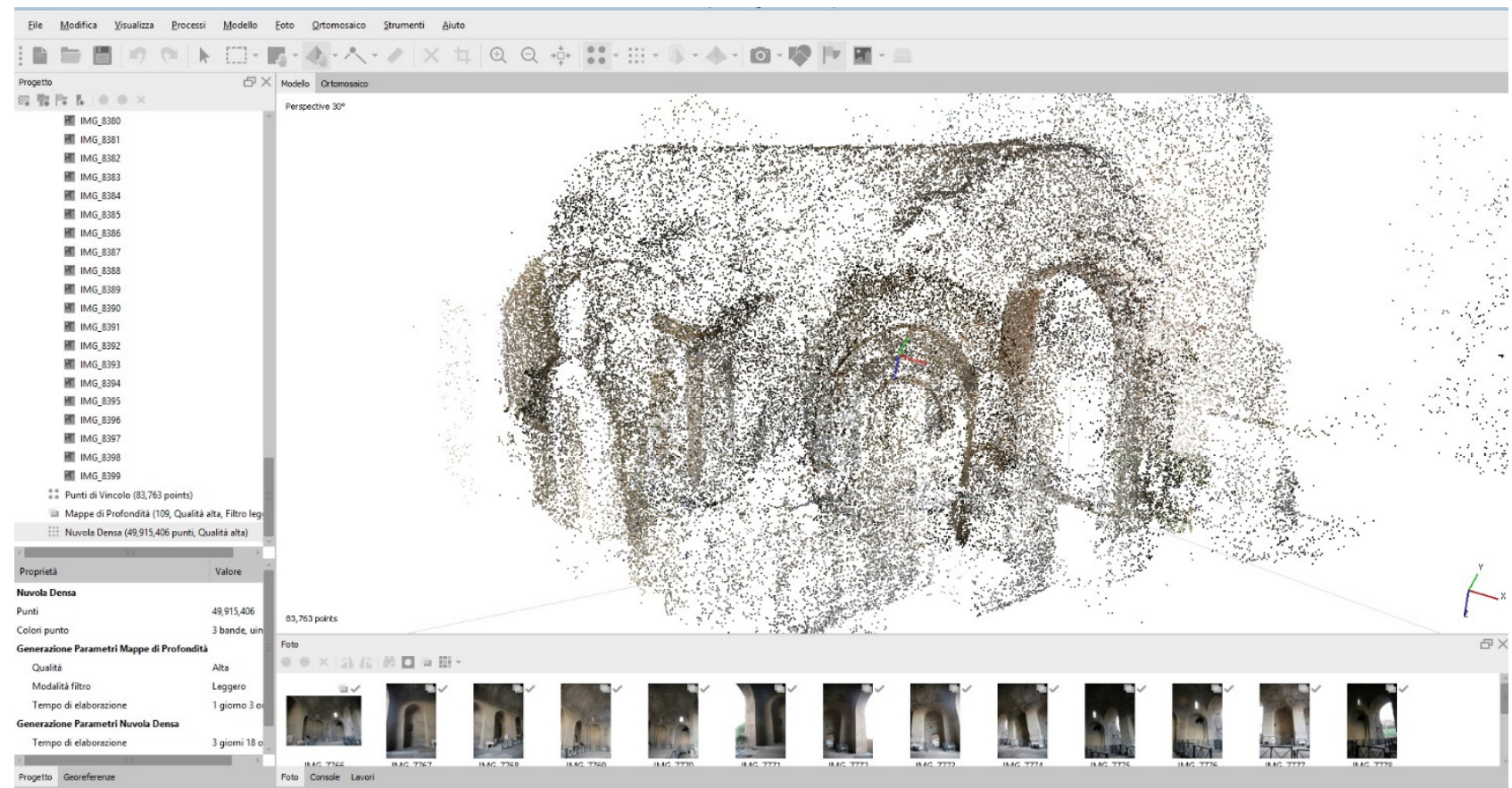

Figure 15: Northwest versura, SFM processing with Metashape.

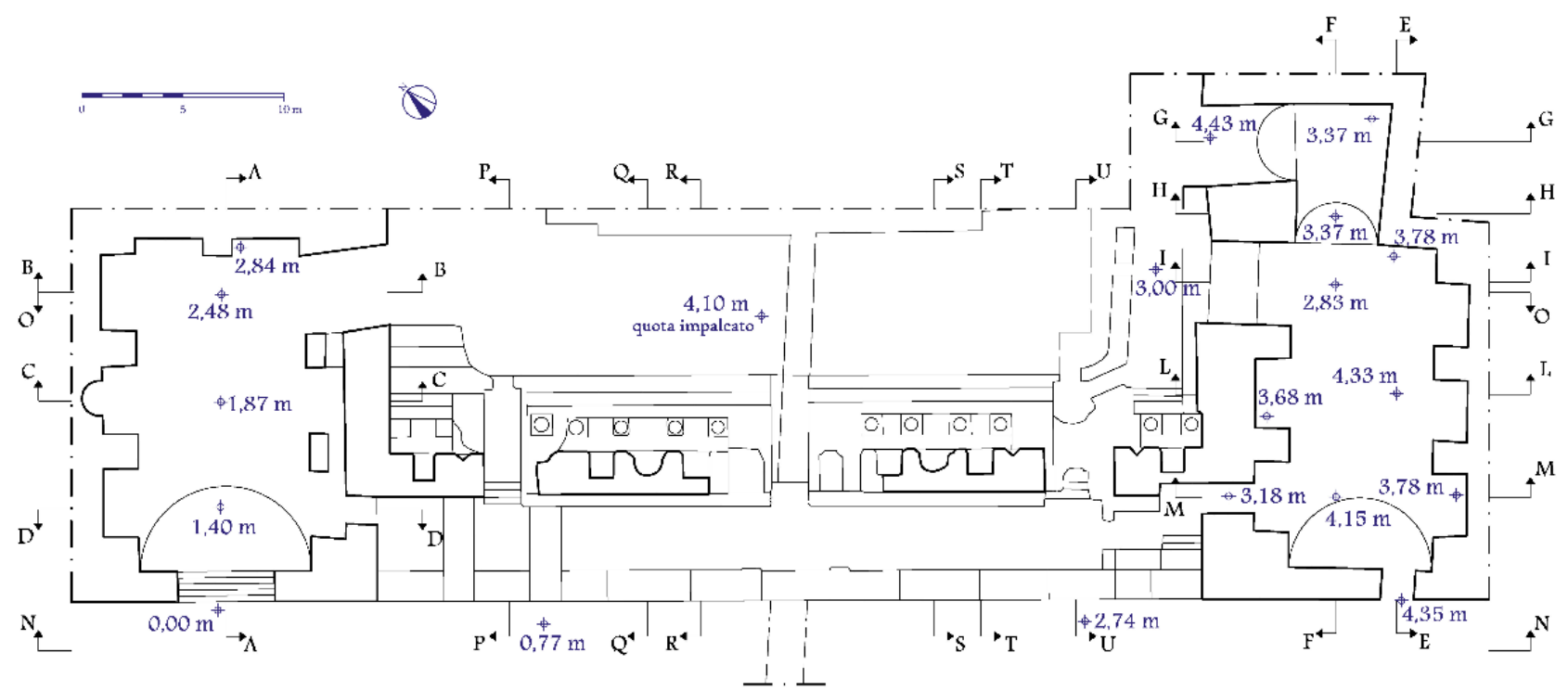

Figure 16: Plan of the scene and the two versurae. 


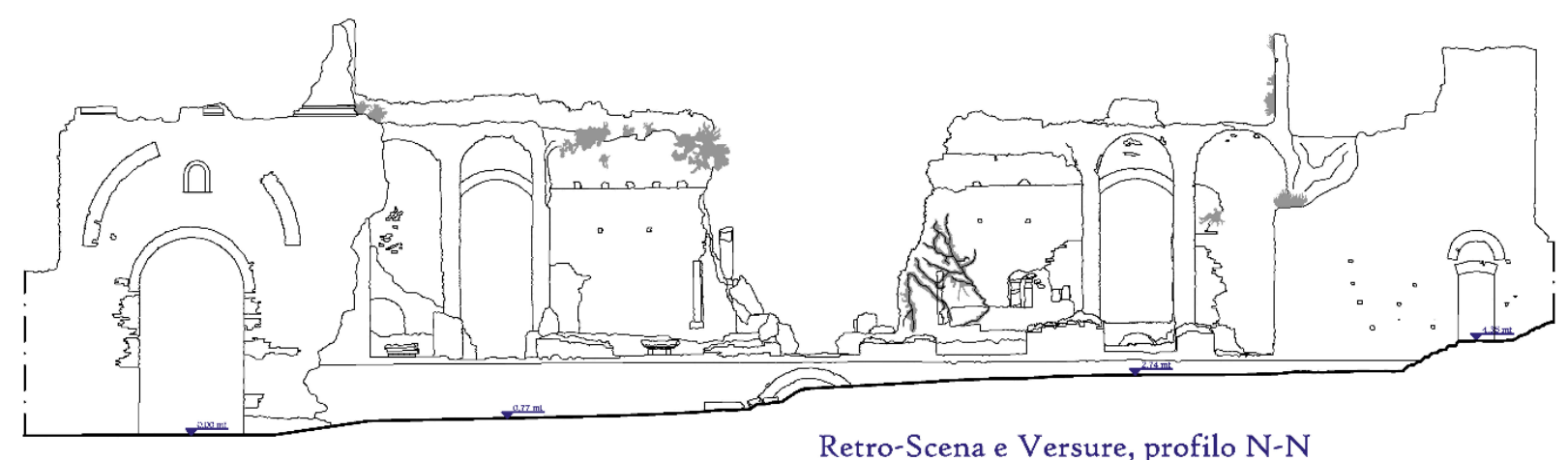

Retro-Scena e Versure, profilo N-N

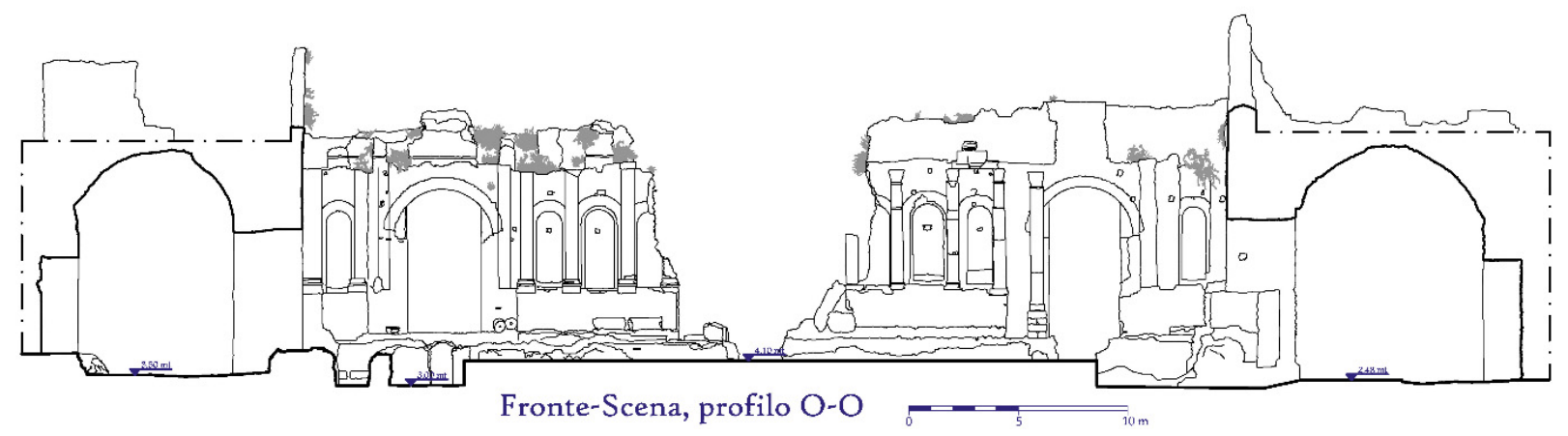

Figure 17: Restitution of the scene from both sides.

\section{Conclusions}

The digital survey that underlies the knowledge and interpretation of this work of man, 3D model and virtual reality is a system of knowledge open over time. Starting from the metric data, from the registered numerical model, the studies can be many and varied, always finding a topic for both cultural and informative study. The development of automatic procedures for the 3D classification of Cultural Heritage it is demanding in architecture and even more so in archeology. Modulations, proportions, signs, drawings, 3D models, virtual reality (VR), augmented reality (AR), are opportunities to deepen the knowledge of this place of entertainment, in that continuous call between the two Latin and Greek cultures, in a continuous research for the key to reading them, for all the things that have been. This site reveals the chosen place for cultural, social exchanges and relations between men and civilizations. A work of man that has survived time and is used today still for the same purposes for which it was intended.

\section{Acknowledgements}

This work was supported by the project "Creazione di una rete regionale per l'erogazione di servizi innovativi basati su tecnologie avanzate di visualizzazione" (3DLabSicilia), Grant No. 08CT4669990220, funded by Operational Program 2014-2020 of the European Regional Development Fund (ERDF) of the Sicilian Region.

\section{References}

Benedetti, B., Gaiani, M., \& Remondino, F. (2010). Modelli digitali 3D in archeologia: il caso di Pompei. Editore Scuola Normale Superiore, Edizioni Pisa, EAN: 9788876423536, ISBN 978-88-7642-353-6.

Farella, E. M., Torresani, A., \& Remondino, F. (2019). Quality Features for integration of and UAV Images. Int. Arch. Photogramm. Remote Sens. Spatial Inf. Sci., XLII-2/W9, 339-346. https://doi.org/10.5194/isprs-archives-XLII-2-W9339-2019

Gallo, A. (1773). Descrizione istorica, ed antiquaria dell'antico teatro di Tavormina.

Grilli, E., \& Remondino, F. (2019). Classification of 3D Digital Heritage. Remote Sens., $11,847$. https://doi.org/10.3390/rs11070847

Houel, J. P. L. (1977). Viaggio in Sicilia e a Malta, "Storia di Napoli e della Sicilia". Società Editrice.

Lo Faso Pietrasanta, D. (1842). Le antichità della Sicilia esposte ed illustrate, presso la reale stamperia, Palermo.

Malinverni, E. S., Pierdicca, R., Paolanti, M., Martini, M., Morbidoni, C., Matrone, F., \& Lingua, A. (2019). Deep learning for semantic segmentation of 3D point cloud. Int. Arch. Photogramm. Remote Sens. Spatial Inf. Sci., XLII-2/W15, 735-742. https://doi.org/10.5194/isprs-archives-XLII-2-W15-735-2019

Matrone, F., Grilli, E., Martini, M., Paolanti, M., Pierdicca, R., \& Remondino, F. (2020). Comparing Machine and Deep Learning Methods for Large 3D Heritage Semantic Segmentation. ISPRS Int. J. Geo-Inf. 2020, $9,535$. 
https://doi.org/10.3390/ijgi9090535

Muscolino, F. (2020). Taormina 1465: la concessione del teatro antico (lu Goliseu alias lu Palazu) come residenza signorile e altri casi di riuso di monumenti antichi nella Sicilia del XV secolo. Mélanges de l'École française de Rome - Moyen Âge. https://doi.org/10.4000/mefrm.6772

Raimondo, G. F. (2009). Rilievo e rappresentazione del Teatro Antico di Taormina tramite Laser Scanner 3D. Tesi di Laurea, Università degli Studi di Catania.

Rizzo, P. (1983). Tauromenion. Salvatore Sciascia editore, Caltanissetta, Roma.

Scarciotta, R. (2009). Rilievo e rappresentazione del Teatro Antico di Taormina tramite Laser Scanner 3D. Tesi di Laurea, Università degli Studi di Catania. 